\title{
Key Technology of the Electrochemical Machining Flow Field in Aero-rotor Blades Made of Inconel ${ }^{\circledR 718}$
}

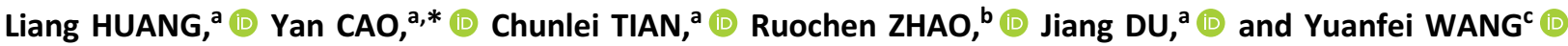

${ }^{a}$ Mechatronic Engineering, Xi'an Technological University, Xi'an, No. 2 Xuefu middle street, Weiyang District, 710021, China

${ }^{b}$ Ministry of Science and Technology, Xi'an Technological University, Xi'an, No. 2 Xuefu middle street, Weiyang District, 710021, China

' Tool Structure Manufacturing, Xi'an KunLun Industry (Group) Company with Limited Liability,

Xi'an, No. 67 Xingfu north street, Xincheng District, 710021, China

*Corresponding author: caoyan@xatu.edu.cn

\section{ABSTRACT}

To address the problems of serious tool loss and the easy deformation of aero-rotor blade profiles in NC milling technology, electrochemical machining can realize the processing of complex, specially structured products with advanced materials such as nickel alloy Inconel ${ }^{\circledR} 718$ by means of a non-contact electrochemical etching process. In this paper, by analysing the electrochemical reaction state of Inconel ${ }^{\circledR 718}$ alloy in vertical electrolytic processing, the electrolyte side flow of aero-blade electrochemical machining technology is innovatively transplanted to the traditional vertical single-axis feed machining tool, and the corresponding optimized flow channel structure that combines the characteristics of positive flow mode and side flow mode are proposed. Then, the verification test shows that the vertical machining of aero-blade with the characteristics of positive flow and side flow of electrolyte has high machining quality, and its surface error is in the range of $0.02-0.12 \mathrm{~mm}$ (the average surface error can reach $0.07 \mathrm{~mm}$ ), the corresponding surface roughness is $1.16 \mu \mathrm{m}$. Therefore, the research foundation and technical potential are laid for the vertical electrochemical machining of the aero-rotor blades.

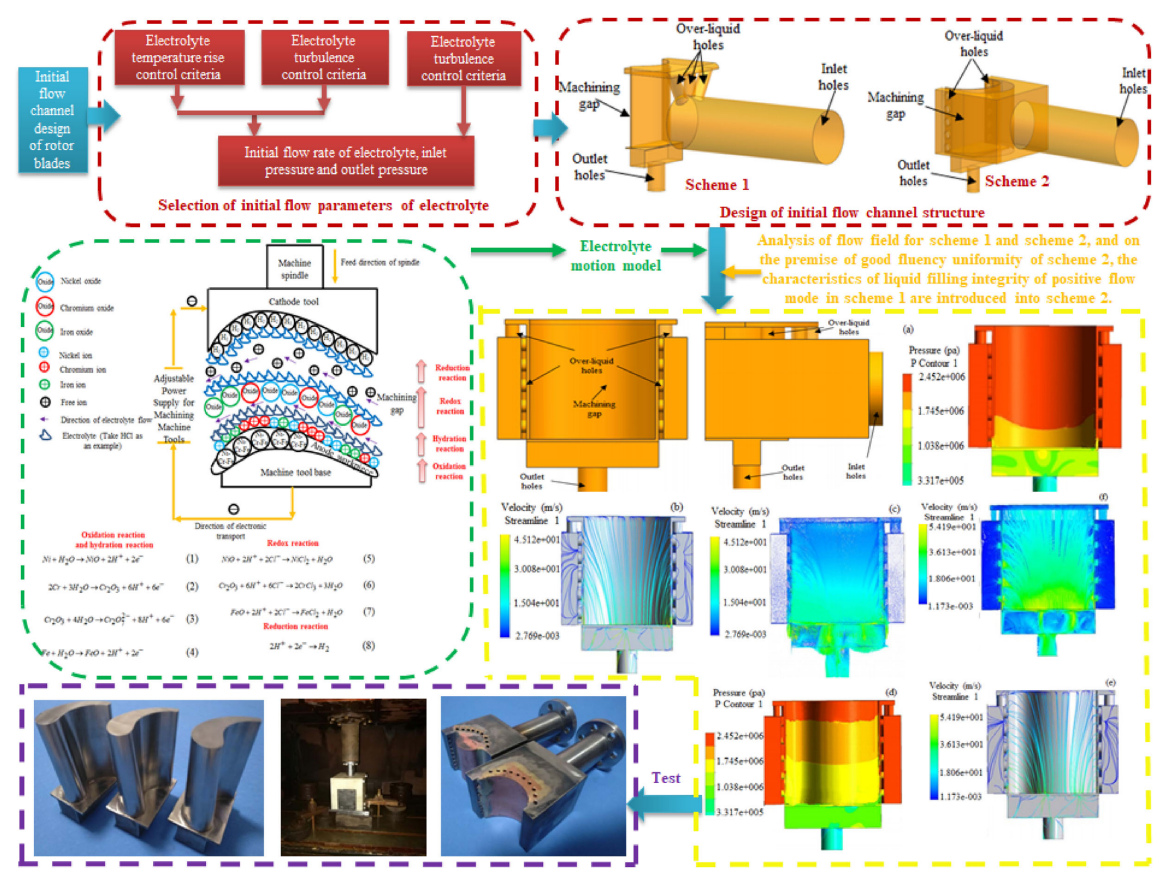

(C) The Author(s) 2021. Published by ECSJ. This is an open access article distributed under the terms of the Creative Commons Attribution 4.0 License (CC BY, http://creativecommons.org/licenses/by/4.0/), which permits unrestricted reuse of the work in any medium provided the original work is properly cited. [DOI: 10.5796/electrochemistry.21-00025].

Keywords : Aero Rotor Blades, Electrochemical Machining, Flow Field, Finite Element Numerical Simulation

\section{Introduction}

As rotor blades are the core component of aero-engines, their quality directly determines the aero-engine performance. ${ }^{1}$ With the

L. Huang (iD) orcid.org/0000-0002-9968-139X

Y. Cao (iD) orcid.org/0000-0002-2959-5533

C. Tian (D) orcid.org/0000-0002-2832-9997

R. Zhao (iD) orcid.org/0000-0002-8039-4710

J. Du (iD orcid.org/0000-0002-2475-2448

Y. Wang (D) orcid.org/0000-0002-5561-7038 development of high-power and high-load aero-rotor engines in recent years, the design of blade structures and high-temperature bearing capacity are more demanding. To this end, researchers have investigated the structural design and mechanical properties of materials to improve the existing blades. ${ }^{2,3}$ On the one hand, the blade structure has been developed with large curvature, high distortion and thin-walls by considering the action of air flow, the thermophysical properties of the gaseous working fluid and the overall structural resistance characteristics. On the other hand, the superalloy materials needed to satisfy the mechanical properties of the new blade structure have been studied, resulting in the 
emergence of a series of superalloy, such as Inconel ${ }^{\circledR} 718$. However, this superalloy material has a high hardness and toughness, and thus, complex-shaped products made with this new superalloy material have serious tool loss and easy deformation of the blade profile in traditional NC milling technology. ${ }^{4}$ Moreover, although the noncontact hot-molten forming technology of electrical discharge machining (EDM) can compensate for the tool loss caused by the NC cutting of high-temperature cemented carbide material, the thermal recasting layer and the heat-affected zone after EDM will interfere with the formation quality of the key parts of the blade surface. ${ }^{5}$ In contrast, electrochemical machining (ECM) is a noncontact electrochemical etching technology that involves clamping the workpiece and the cathode tool in opposite positions and connecting them to positive and negative electrodes of the external power supply of the machine tool, respectively (as shown in Fig. 1, this paper uses vertical electrochemical machining as an example). On the one hand, the anode material is oxidized into an ionic conductor by using the potential energy of the power supply. On the other hand, the electrons transmitted through the power supply cause the metal atoms in the metal cathode to transition and form electronic conductors, resulting in conduction of the anode electron to the cathode surface and formings the interpolar potential. The Inconel ${ }^{\circledR} 718$ superalloy is a Ni-Cr-Fe-based alloy that enables the anode alloy ions in the machining gap to move in a directional manner under the action of the external power supply potential. These ions produced on the anode surface are then converted into free ions by a hydration reaction and a redox reaction under the action of electrolyte flow in the machining gap, while the electrons obtained on the cathode surface make a large number of hydrogen ions in the aqueous solution as the surrounding electrolyte accepts electrons and produces hydrogen. This step completes the process of etching the whole anode material, which can solve the problems of traditional $\mathrm{NC}$ milling by enhancing the properties of workpiece materials, minimizing the loss of the tool cathode and achieving a high machining efficiency. ${ }^{6}$ Electrochemical machining uses highspeed electrolytes to replace EDM with high-temperature breakdown discharge melting by electrochemical etching, thus avoiding the influence of the thermal recasting layer and heat-affected zone on the moulding quality to obtain an excellent surface. ${ }^{7}$ However, for electrochemical machining, the electrochemical etching of anode materials is completely based on the electrochemical characteristic distribution of the electrolyte in the machining gap. This distribution is determined by the electrolyte flow channel structure by controlling the fluid mass transfer process and finally acting on the formation quality through the distribution of electrochemical etching characteristics on various parts of the machining surface, therefore, the rational design and optimization of the flow channel are of great significance in the process of ECM.

The design and analysis of the flow field of the aero-rotor blade has been a hot research topic in the field of electrochemical machining in recent years. To date, some scholars have carried out a series of studies on this topic, In the area of flow field structure design, Zhu et al. ${ }^{8}$ proposed a new dynamic lateral flow mode of the electrolyte, in which the electrolyte flows from the leading edge to the trailing edge by trepanning the ECM of a diffuser; this flow field can achieve the precision machining of a surface up to $0.12 \mathrm{~mm}$ under the condition of a uniform flow field distribution in the electrode gap; $\mathrm{Xu}$ et al. ${ }^{9}$ proposed a two-way flow mode of the electrolyte under the single-edge plate blade, that is, the flow of electrolyte from both sides of the edge plate and through the blade basin and the blade back channel; the numerical simulation method and the experimental verification method were compared with the traditional side flow mode to verify the improvement in the uniformity and stability of the flow field by using the active control flow mode. Subsequently, Liu et al. ${ }^{10}$ of Nanjing University of Aeronautics and Astronautics proposed a three-dimensional composite electrolyte flow pattern for the whole blade disk. Based on this study, Sawicki et al. ${ }^{11}$ optimized the flow field uniformity

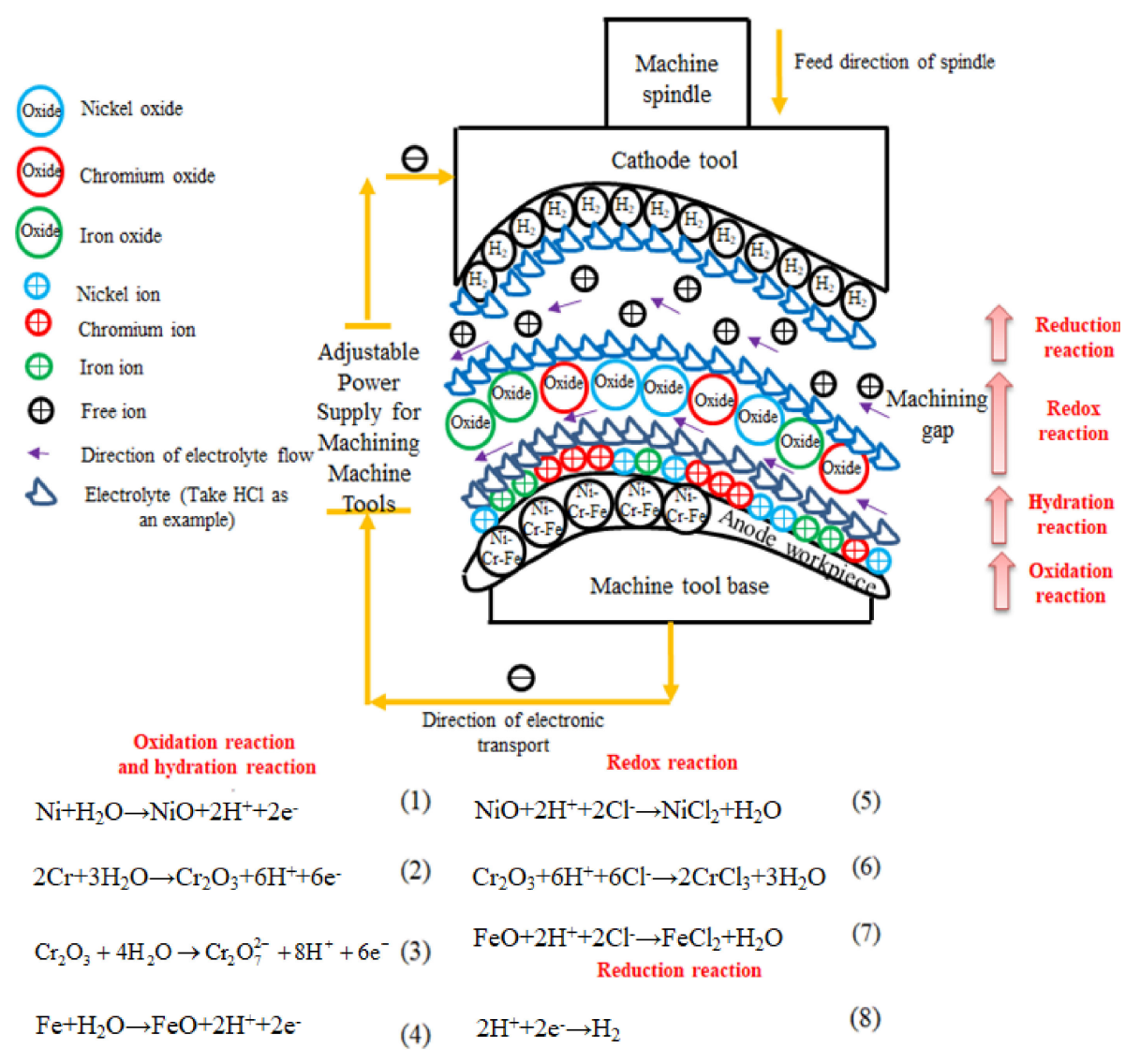

Figure 1. Schematic diagram of the electrochemical machining of Inconel ${ }^{\circledR} 718$ aero-rotor blades. 
distribution by adjusting the machining gap and flow velocity in the process of side flow machining on the blade surface. The numerical simulation of flow fields, by associating fluid flow, fluid heat transfer and energy conservation, Chen et al. ${ }^{12}$ established an interdisciplinary simulation model for the electrochemical machining process of aero-engine blades, and verified the rationality and accuracy of the proposed simulation model by using optical in situ measurements. The effects of flow field parameters on the machining clearance were analyzed by correlating the turbulence model of a k-epsilon flow channel with the dual Euler model considering viscous resistance and pressure, and the predicted machining clearance was consistent with the experimental results (the maximum deviation was less than $50 \mu \mathrm{m})$.

According to the above literature, the design and simulation of aero-rotor blades flow field are mainly optimized and improved on the basis of electrolyte side flow mode of horizontal machining machine tool. However, the flow channel design of electrolyte side flow machining on vertical machining machine tool is still less. Therefore, by combining the existing traditional vertical single-axis feed machining mode with the traditional side flow processing blade flow characteristics, this paper innovatively proposes two electrolyte flow schemes under the vertical machining mode; Then, based on the above two flow channel structures and the energy loss characteristics of viscous fluid during liquid-phase mass transfer, a mathematical model of the liquid phase mass transfer flow field is established that combines the viscosity loss characteristics of the electrolyte. By introducing an optimized flow channel structure that combines characteristics of positive flow and side flow and adjus the parameters of the electrolyte inlet/outlet, the optimal design channel structure and uniform flow field of aero-rotor blades are achieved. Finally, the accuracy and rationality of the proposed scheme are verified by electrochemical machining verification tests, which lay a research foundation and potential for the feasibility and accuracy of vertical electrochemical machining machine tools in the manufacturing of aero-rotor blades.

\section{Experimental}

In this paper, a small engine aero-rotor blade produced by Xi'an KunLun Industry (Group) Company, Ltd., is taken as the research object (the material element composition of the blade is shown in Table 1, which meets the ASTM F3055-14a standard). This rotor was chosen to ensure high corrosion efficiency and to avoid both the effect of flocculation precipitation of neutral electrolyte on the corrosion conductivity and the formation of insoluble dense oxide film by the alkaline solution on the surface of the anode workpiece. Based on the polarization curves of conductivity studies of acid electrolytes, ${ }^{13}$ hydrochloric acid with a concentration of $0.1 \mathrm{M}$ was selected as electrolyte solution. Then, by using the control variable method and according to the adjustable range of power supply parameters of the DIASINKER-3550 single-axis vertical electrolytic machining tool, the DDS-307 conductivity measuring instrument was used to determine the highest current and efficiency of $0.1 \mathrm{M} \mathrm{HCl}$ electrolyte at a machining voltage of $15 \mathrm{~V}$ and the first stable working efficiency was determined. Finally, using formula (9), which takes into account the current density and the current efficiency, corrosion removal under the corresponding current efficiency with different current densities was calculated (as show in Fig. 2), and the corresponding adjustable parameters for using DIASINKER-3550 single-axis vertical electrolytic machining under a stable current efficiency was selected at $25^{\circ} \mathrm{C}$, feed rate of $0.3 \mathrm{~mm} / \mathrm{min}$, pressure pump adjustable input pressure at $0-2.5 \mathrm{MPa}$, applied voltage of $15 \mathrm{~V}$, and current density of $40 \mathrm{~A} \mathrm{~cm}^{-2}$;

$$
v_{\mathrm{a}}=\eta w i
$$

Table 1. Material element composition of the Inconel ${ }^{\circledR} 718$ aerorotor blades.

\begin{tabular}{cc}
\hline Element & Content/wt\% \\
\hline $\mathrm{Al}$ & 0.42 \\
$\mathrm{~B}$ & 0.0054 \\
$\mathrm{~S}$ & 0.010 \\
$\mathrm{Co}$ & 0.22 \\
$\mathrm{Cr}$ & 19.13 \\
$\mathrm{Cu}$ & 0.042 \\
$\mathrm{P}$ & 0.0094 \\
$\mathrm{Ti}$ & 0.89 \\
$\mathrm{Fe}$ & 17.85 \\
$\mathrm{C}$ & 0.044 \\
$\mathrm{Si}$ & 0.17 \\
$\mathrm{Mn}$ & 0.09 \\
$\mathrm{Mo}$ & 2.97 \\
$\mathrm{Nb}+\mathrm{Ta}$ & 5.35 \\
$\mathrm{Ni}$ & residue \\
\hline
\end{tabular}

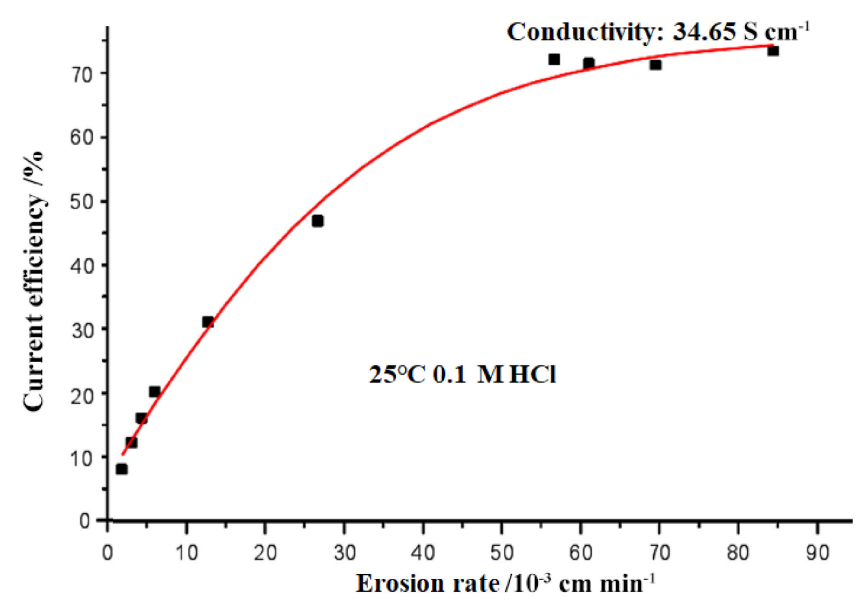

Figure 2. Experimental $v_{\mathrm{a}}-\eta$ relationship curve of the $\mathrm{HCl}$ electrolyte.

where $i$ represents the current density; $\eta$ represents the current efficiency; $w$ represents the electrochemical volumetric equivalent.

Based on the above three-dimensional model and mathematical models of the flow channel, this paper based on the Windows 10 operating system and used the ICEM module in the ANSYSWorkbench 16.0 software library to mesh the flow channel model, and then introduces the mesh model into the CFX module to simulate the flow channel model. Finally, the flow cloud diagram of electrolyte is obtained by using Contour command in the postprocessing module, and the initial flow field structure is optimized based on the results.

\section{Analysis and Design of the Vertical Electrochemical Machining Flow Field Characteristics of Aero-rotor Blades}

\subsection{Analysis of the vertical electrochemical machining flow field characteristics of aero-rotor blades}

\subsubsection{Mechanism of the flow field}

The flow rate of the electrolyte plays a key role in the process of controlling the corresponding etching process through liquid mass transfer in each part of the machining gap. On the one hand, in order to strengthen the liquid mass transfer process and ion reaction 
process in the machining gap, it is necessary to make the flow field in the machining gap have a higher flow rate in the turbulent state. On the other hand, Deconinck et al. ${ }^{14}$ found that bubble rate accelerates and that the electrochemical energy that accumulates throughout the process is produced by liquid mass transfer and gasliquid two-phase flow in the processing gap, and the coupling effect of these products affects the final formation quality by acting on the conductivity of electrolyte; therefore, a higher electrolyte flow rate is helpful to ensure the smooth discharge of electrolytic products. The pressure of the electrolyte at the inlet is an important condition that influences the electrolyte flow rate. In addition, when the electrolyte temperature in the machining gap is too high, the electrolyte may exhibit partial boiling or even evaporation in the gap, while when the electrolyte temperature is too low, the anode surface may undergo passivation. Therefore, it is necessary to control the temperature of the machining gap through changing the flow rate. Because the pressure of the electrolyte at the inlet is an important factor for controlling the electrolyte flow rate, the following temperature rise criteria and turbulence criteria for controlling the electrolyte flow rate are established.

Criteria I: According to formula (10), controlling the temperature rise determines the inlet velocity of the machining gap;

$$
u_{0}=\frac{i^{2}}{\rho_{1} \kappa_{0} C_{1} \Delta T} L
$$

where, $i$ represents the current density; $u_{0}$ represents the inlet velocity of the electrolyte; $\kappa_{0}$ represents the initial conductivity of the electrolyte; $L$ represents the electrolyte flow length, $\Delta T$ represents the temperature rise of the electrolyte; $\rho_{1}$ represents the density of the electrolyte; $C_{1}$ represents the heat capacity of the electrolyte.

Criteria II: To ensure that the electrolyte is in a turbulent state, the corresponding flow rate should meet the following formula:

$$
u_{R e}>2300 \frac{v}{D_{\mathrm{h}}}
$$

Where, Re represents the Reynolds number; $D_{\mathrm{h}}$ represents the hydraulic diameter; $v$ represents the kinematic viscosity of the electrolyte.

The flow rate of the machining gap can be determined by combining the above two criteria:

$$
u \geq \max \left\{u_{R \mathrm{e}}, u_{0}\right\}
$$

To ensure that the electrolyte in the gap has a sufficient flow rate, it is necessary to add a certain pressure at the inlet of the gap. The added pressure should be the sum of the dynamic pressure, viscous friction force and outlet back pressure, so the input pressure corresponding to the inlet velocity is obtained from the Bernoulli equation of the actual fluid as follows, the initial flow rate $u_{0}$ is $15 \mathrm{~m} \mathrm{~s}^{-1}$, the inlet pressure $P_{\mathrm{A}}$ is $1.476 \mathrm{MPa}$ and the outlet pressure $P_{\mathrm{B}}$ is $0.2 \mathrm{MPa}$.

$$
\begin{aligned}
P_{\mathrm{A}} & +\frac{a_{\mathrm{A}} \rho_{1} u_{0}^{2}}{2 g}+\rho_{1} Z_{\mathrm{A}} \\
& =P_{\mathrm{B}}+\frac{a_{\mathrm{B}} \rho_{1} u^{2}}{2 g}+\rho_{1} Z_{\mathrm{B}}+\rho_{1} \sum H
\end{aligned}
$$

Where, $a_{\mathrm{A}}$ and $a_{\mathrm{B}}$ are the flow parameters of the gap inlet and outlet, respectively; and $\sum H$ is the head loss of the fluid per unit weight. 3.1.2 Mathematical model of the flow field

To ensure that the movement of the electrolyte in the above electrolytic flow channel is turbulent and considering that the electrolyte should have the Newtonian fluid characteristics of lowmolecular weight compounds in solution (in this paper, Inconel ${ }^{\circledR} 718$ super-alloy was used as the blade material and $0.1 \mathrm{M} \mathrm{HCl}$ solution was used as the electrolyte), in this paper, the mass continuity equation (as shown in formula (14)) and momentum conservation model (as shown in formula (15)) of the viscous Newtonian fluid were established. The instantaneous velocity $u$ in the above two turbulent motion models was replaced by the sum of the average velocity $\bar{u}$ and fluctuating velocity $u^{\prime}$ at this time, and the above two models were combined and temporally homogenized to transform them into the corresponding Reynolds equations (as shown in formula (16)). Because formula (16) introduces a variable with a pulsating velocity correlation distance and represents the dynamic transport rate per unit area of the traversing fluid caused by turbulent vortex pulsation, to ensure the solvability of the variable, the solvable flow field model for the viscous Newtonian fluid in runner motion is obtained (as shown in formula (17)) based on the modified zero-square model $\left(k^{1 / 2}=\sqrt{u_{\mathrm{i}} u_{\mathrm{i}} / 2} \varepsilon=\frac{v}{\rho_{1}} \overline{\left(\frac{\partial u_{\mathrm{i}}}{\partial x_{\mathrm{k}}}\right)\left(\frac{\partial u_{\mathrm{i}}}{\partial x_{\mathrm{k}}}\right)}\right)$ proposed by Kolmogorov $^{15}$ and the generalized turbulent transport parameter model $\left(Z=k^{m} l^{n}\right)$ established by circuitous tactics;

$$
\frac{\partial \rho_{1}}{\partial t}+\frac{\partial\left(\rho_{1} u_{\mathrm{x}}\right)}{\partial x}+\frac{\partial\left(\rho_{1} u_{\mathrm{y}}\right)}{\partial y}+\frac{\partial\left(\rho_{1} u_{\mathrm{z}}\right)}{\partial z}=0
$$

where, $u_{x}, u_{y}$, and $u_{z}$ represent the components of the velocity $u$ on $x$ axis, $y$-axis, and $z$-axis, respectively;

$$
\left\{\begin{array}{l}
\frac{\partial u_{\mathrm{x}}}{\partial t}+u_{\mathrm{x}} \frac{\partial u_{\mathrm{x}}}{\partial x}+u_{\mathrm{y}} \frac{\partial u_{\mathrm{x}}}{\partial y}+u_{\mathrm{z}} \frac{\partial u_{\mathrm{x}}}{\partial z}=f_{\mathrm{x}}-\frac{1}{\rho_{1}} \frac{\partial p}{\partial x}+v\left[\frac{\partial^{2} u_{\mathrm{x}}}{\partial x^{2}}+\frac{\partial^{2} u_{\mathrm{x}}}{\partial y^{2}}+\frac{\partial^{2} u_{\mathrm{x}}}{\partial z^{2}}\right] \\
\frac{\partial u_{\mathrm{y}}}{\partial t}+u_{\mathrm{x}} \frac{\partial u_{\mathrm{y}}}{\partial x}+u_{\mathrm{y}} \frac{\partial u_{\mathrm{y}}}{\partial y}+u_{\mathrm{z}} \frac{\partial u_{\mathrm{y}}}{\partial z}=f_{\mathrm{y}}-\frac{1}{\rho_{1}} \frac{\partial p}{\partial y}+v\left[\frac{\partial^{2} u_{\mathrm{y}}}{\partial x^{2}}+\frac{\partial^{2} u_{\mathrm{y}}}{\partial y^{2}}+\frac{\partial^{2} u_{\mathrm{y}}}{\partial z^{2}}\right] \\
\frac{\partial u_{\mathrm{z}}}{\partial t}+u_{\mathrm{x}} \frac{\partial u_{\mathrm{z}}}{\partial x}+u_{y} \frac{\partial u_{\mathrm{z}}}{\partial y}+u_{\mathrm{z}} \frac{\partial u_{\mathrm{z}}}{\partial z}=f_{\mathrm{z}}-\frac{1}{\rho_{1}} \frac{\partial p}{\partial z}+v\left[\frac{\partial^{2} u_{\mathrm{z}}}{\partial x^{2}}+\frac{\partial^{2} u_{\mathrm{z}}}{\partial y^{2}}+\frac{\partial^{2} u_{\mathrm{z}}}{\partial z^{2}}\right]
\end{array}\right.
$$

where, $f_{\mathrm{x}}$ represents the mass force of the electrolyte; $p$ represents the pressure of the electrolyte, $v$ represents the viscosity of electrolyte, and;

$$
\begin{aligned}
& \left\{\begin{array}{l}
\frac{\partial \overline{u_{\mathrm{x}}}}{\partial t}+\overline{u_{\mathrm{x}}} \frac{\partial \overline{u_{\mathrm{x}}}}{\partial x}+\overline{u_{\mathrm{y}}} \frac{\partial \overline{u_{\mathrm{x}}}}{\partial y}+\overline{u_{\mathrm{z}}} \frac{\partial \overline{u_{\mathrm{x}}}}{\partial z}=f_{\mathrm{x}}-\frac{1}{\rho_{1}} \frac{\partial \bar{p}}{\partial x}+v \nabla^{2} u_{\mathrm{x}}-\frac{\partial \overline{u_{\mathrm{x}}^{\prime} u_{\mathrm{x}}^{\prime}}}{\partial x}-\frac{\partial \overline{u_{\mathrm{y}}^{\prime} u_{\mathrm{x}}^{\prime}}}{\partial y}-\frac{\partial \overline{u_{\mathrm{z}}^{\prime} u_{\mathrm{x}}^{\prime}}}{\partial z} \\
\frac{\partial \overline{u_{\mathrm{y}}}}{\partial t}+\overline{u_{\mathrm{x}}} \frac{\partial \overline{u_{\mathrm{y}}}}{\partial x}+\overline{u_{\mathrm{y}}} \frac{\partial \overline{u_{\mathrm{y}}}}{\partial y}+\overline{u_{z}} \frac{\partial \overline{u_{\mathrm{y}}}}{\partial z}=f_{\mathrm{y}}-\frac{1}{\rho_{1}} \frac{\partial \bar{p}}{\partial x}+v \nabla^{2} u_{\mathrm{y}}-\frac{\partial \overline{u_{\mathrm{x}}^{\prime} u_{\mathrm{y}}^{\prime}}}{\partial x}-\frac{\partial \overline{u_{\mathrm{y}}^{\prime} u_{\mathrm{y}}^{\prime}}}{\partial y}-\frac{\partial \overline{u_{\mathrm{z}}^{\prime} u_{\mathrm{y}}^{\prime}}}{\partial z} \\
\frac{\partial \overline{u_{\mathrm{z}}}}{\partial t}+\overline{u_{\mathrm{x}}} \frac{\partial \overline{u_{\mathrm{z}}}}{\partial x}+\overline{u_{\mathrm{y}}} \frac{\partial \overline{u_{\mathrm{z}}}}{\partial y}+\overline{u_{\mathrm{z}}} \frac{\partial \overline{u_{\mathrm{z}}}}{\partial z}=f_{\mathrm{y}}-\frac{1}{\rho_{1}} \frac{\partial \bar{p}}{\partial x}+v \nabla^{2} u_{\mathrm{z}}-\frac{\partial \overline{u_{\mathrm{x}}^{\prime} u_{\mathrm{z}}^{\prime}}}{\partial x}-\frac{\partial \overline{u_{\mathrm{y}}^{\prime} u_{\mathrm{z}}^{\prime}}}{\partial y}-\frac{\partial \overline{u_{\mathrm{z}}^{\prime} u_{\mathrm{z}}^{\prime}}}{\partial z} \\
\frac{\partial\left(\rho_{1} k\right)}{\partial t}+\frac{\partial\left(\rho_{1} k u_{\mathrm{i}}\right)}{\partial t}=\frac{\partial}{\partial x_{\mathrm{j}}}\left[\left(v+\rho_{1} C_{\mathrm{v}} \frac{k^{2}}{\varepsilon \sigma_{\mathrm{k}}}\right) \frac{\partial k}{\partial x_{\mathrm{j}}}\right]-\rho_{1} \varepsilon+G_{\mathrm{k}}+G_{\mathrm{b}} \\
\frac{\partial\left(\rho_{1} \varepsilon\right)}{\partial t}+\frac{\partial\left(\rho_{1} k u_{\mathrm{i}}\right)}{\partial t}=\frac{\partial}{\partial x_{\mathrm{j}}}\left[\left(v+\rho_{1} C_{\mathrm{v}} \frac{k^{2}}{\varepsilon \sigma_{\varepsilon}}\right) \frac{\partial \varepsilon}{\partial x_{\mathrm{j}}}\right]+C_{1 \varepsilon} \frac{\varepsilon}{k}\left(G_{\mathrm{k}}+C_{3 \varepsilon} G_{\mathrm{b}}\right)-C_{2 \varepsilon} \rho_{1} \frac{\varepsilon^{2}}{k}
\end{array}\right.
\end{aligned}
$$


where, $C_{\mathrm{V}}$ represents the empirical constants of fluid viscosity; $\sigma_{\mathrm{k}}$ and $\sigma_{\varepsilon}$ are the Prandtl numbers corresponding to turbulent kinetic energy $k$ and dissipation rate $\varepsilon$, respectively; $G_{\mathrm{k}}, G_{\mathrm{b}}$ represents the generation term of turbulent kinetic energies caused by the mass and electrolyte pressure, respectively; $C_{1 \varepsilon}, C_{2 \varepsilon}, C_{3 \varepsilon}$ represents the model empirical constant, ${ }^{16}$ whose specific values, and here, $C_{1 \varepsilon}, C_{2 \varepsilon}, C_{3 \varepsilon}$ are $1.44,1.92,0.92$ respectively; $\sigma_{\mathrm{k}}, \sigma_{\mathrm{b}}$ are $1.0,1.3$ respectively.

\subsection{Design of the vertical electrochemical machining flow field structure of aero-rotor blades}

\subsubsection{Selection of the electrolyte flow mode}

Based on the relationship between the cathode and electrolyte flow, the electrolyte flow can be divided into positive flow, side flow and reflux flow. In the process of traditional blade electrochemical machining, side flow from the inlet (outlet) edge is usually adopted. The electrolyte side flow machining of an aero-rotor blade is mainly carried out on horizontal electrolytic machining machine tool. When the anode workpiece is fixed in the middle of the blade basin cathode tool and the blade back cathode tool, the distance between the anode workpiece and the cathode tool is the corresponding machining gap. And the electrolyte flows into the blade basin machining gap and the blade back machining gap from one side of the machining gap respectively, and finally flows out after collecting on the other side of the machining gap. The formation of the whole blade can be completed by simultaneously feeding the blade back cathode tool and the blade basin cathode tool to the anode workpiece (as shown in Fig. 3). The advantages of this electrolyte flow mode are more prominent in the processing of blades with less distortion on the surface. Because of the small distortion of the blades, the electrolyte flows smoothly in the flow channel, and the changes in the electrolyte flow rate and flow pressure are slow and uniform. However, there are still some defects in this flow mode that need to be optimized. As shown in Fig. 4, when the electrolyte flows through the gap, part of the electrolyte will rebound by the side of the gap, which makes the flow field very disordered at the entrance of the machining gap, resulting in an unstable processing process, and the electrolyte flow rates flowing through the blade basin and blade back are unpredictable and passive. ${ }^{17}$

To solve the above problems, combined with the structure of a vertical electrolytic machining machine tool, the processing modes of the blade basin and blade back are adopted (this paper uses the processing of the blade back surface as an example), which can control the electrolyte flow rate. Moreover, in addition to fixing the machined surface of the anode workpiece to the base of the machine tool, the cathode is fixed to the spindle of the machine tool, and the electrolysis of each surface of the blade is completed by vertically feeding the cathode and the spindle together (as shown in Fig. 5, the component reactions in the corresponding processing processes are shown in Fig. 1). In this paper, two electrolyte flow modes are designed as shown in Fig. 5. Scheme 1: the electrolyte flows from

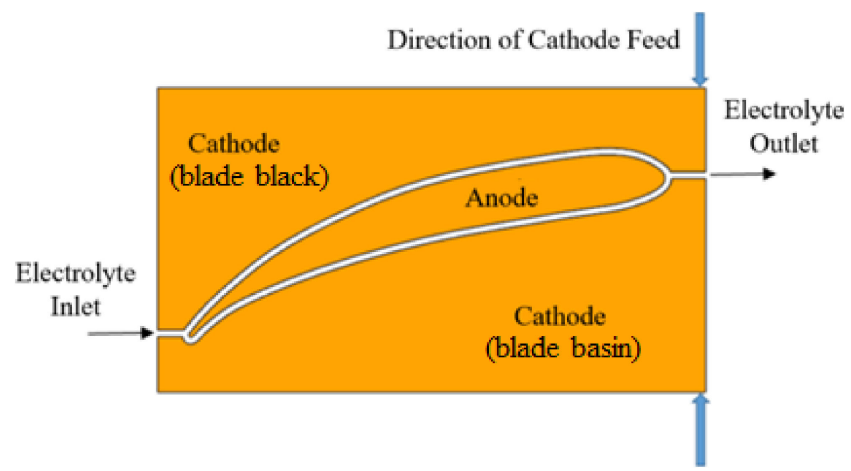

Figure 3. Schematic diagram of a traditional side flow electrochemically machined blade (top view). the main axis, through the over-liquid hole above the cathode into the gap between the blade edge and the cathode, from the end of the blade to the blade body, finally from the tip of the blade; Scheme 2: the electrolyte flows from the main axis to the over-liquid hole of the cathode side; both sides flow to the blade body at the same time, and then they flow from the tip of the blade.

\subsubsection{Design of the cathode tool flow channel structure}

The flow field simulation analysis is based on the distribution of electrolyte in the flow channel, so it is necessary to construct a solid model of the electrolyte distribution. First, the cathode structure is designed. To ensure that the liquid in the channel is sufficient and has the correct amount of back pressure, the area of the liquid outlet should meet the requirements of having a smaller area than the inlet and a larger area than the outlet. Combined with the above flow modes, the corresponding cathode structures are shown in Fig. 6.

\subsubsection{Design of the fixture flow channel structure}

The fixture must be a well-sealed cavity so that the electrolyte can maintain a high flow rate through the machining gap to smoothly discharge the anodic dissolution products and process heat to ensure the processing stability. Furthermore, during electrolytic processing, the flow mode of the electrolyte depends on the design of the fixture, so this paper designs a blade machining fixture for vertical machine tool (as shown in Fig. 7) based on the above two

\section{Flow direction of electrolyte}

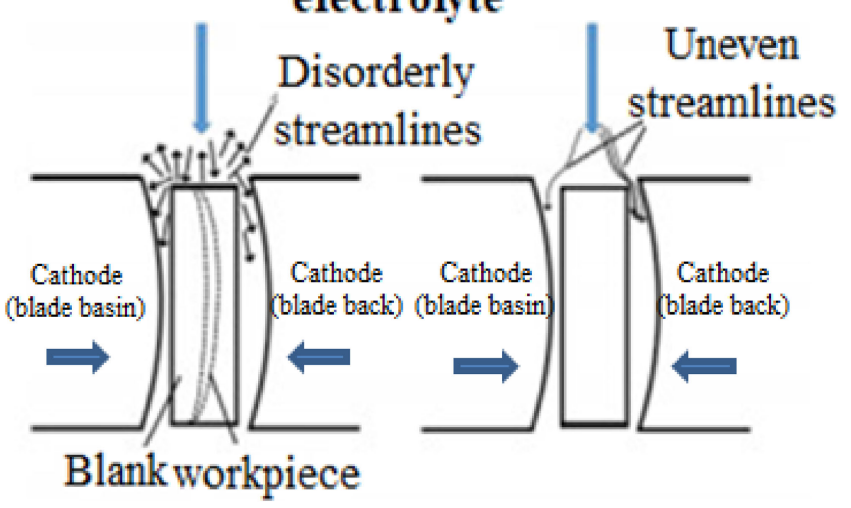

Figure 4. Schematic diagram of Scheme 1 electrolyte flow (front view).
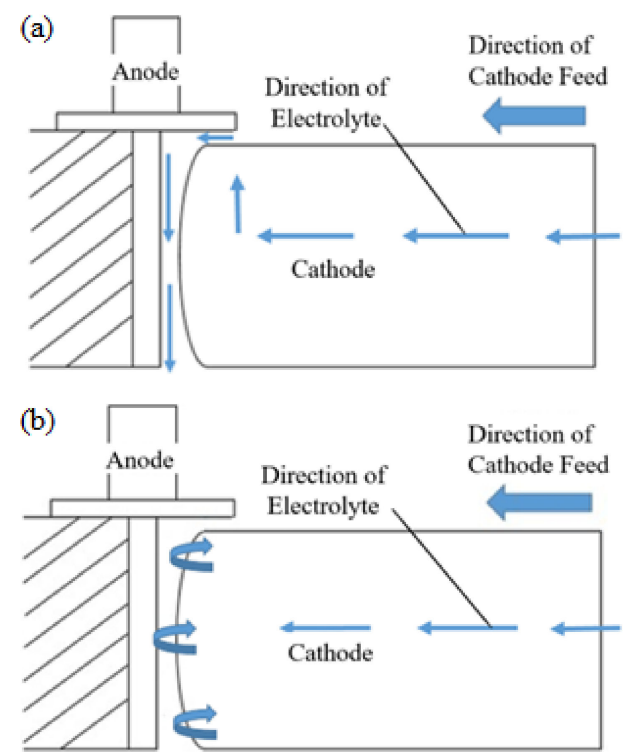

Figure 5. Schematic diagram of electrolyte flow (front view). (a) Scheme 1 and (b) Scheme 2. 

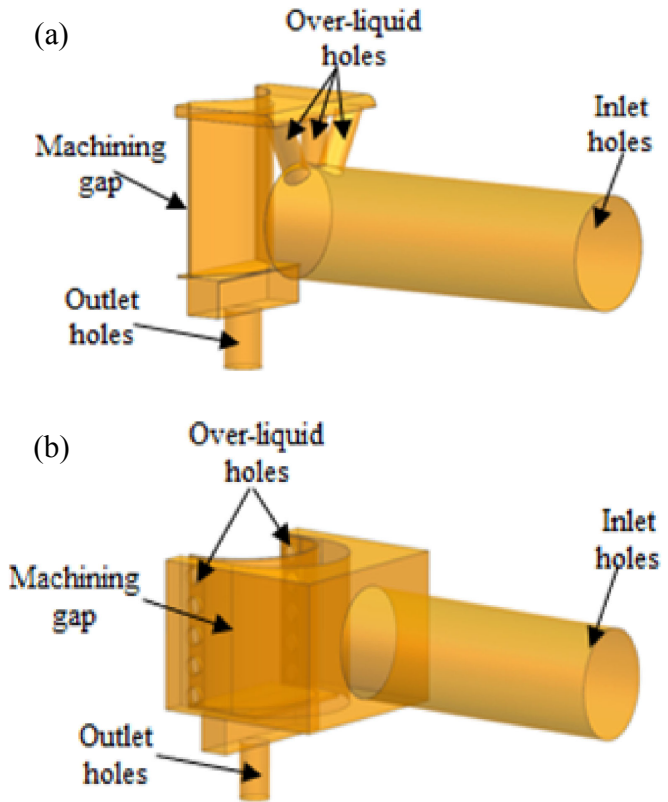

Figure 6. Cathode tool flow channel structure. (a) Scheme 1 and (b) Scheme 2.

electrolyte flow modes, the sizes of the inlet and outlet, and the relationship among the inlet area, outlet area and over-liquid area.

\section{Results and Discussion}

\subsection{Initial flow field analysis of aero-rotor blades for vertical electrochemical machining}

In the pressure analysis of the flow field: Figs. 8(a) and 8(b) show the pressure distribution clouds when the electrolyte enters the flow channel of Scheme 1 and Scheme 2. In Scheme 1, the pressure decreases obviously when the electrolyte flows into the machining gap, and the sudden change in the pressure easily produces cavities. In contrast, in the Scheme 2, the change in the pressure gradient is more uniform when the electrolyte flows into the machining gap.

In a flow velocity analysis of the flow field: Figs. 8(c) and 8(d) show the streamline distribution diagrams of electrolyte entry into the flow channel of the Scheme 1 and Scheme 2, respectively. The velocity of the electrolyte in the machining gap of Scheme 1 is approximately $25 \mathrm{~m} \mathrm{~s}^{-1}$, and meets the turbulence condition, but when the electrolyte flows into the machining gap, the velocity mutation is large and the distribution is not uniform; However, in Scheme 2, the flow rate of the electrolyte in the machining gap is approximately $10 \mathrm{~m} \mathrm{~s}^{-1}$, which does not meet the turbulence condition. At the same time, the velocity of the electrolyte increases with an increase in the processing length, and a vortex forms at the maximum curvature of the back of the blade, leading to insufficient supply. Figures $8(\mathrm{e})$ and $8(\mathrm{f})$ show the velocity vector diagrams of when the electrolyte enters the flow channel of Scheme 1 and Scheme 2, respectively. It can be observed that the streamline direction of the electrolyte at the entrance of the machining gap is messy and has a certain effect on the stability of the machining. In Scheme 2, messy streamlines appears at the electrolyte outlet of the machining gap and are mainly concentrated in the nonprocessing area, so this streamline distribution mode has little effect on the flow field stability in the machining gap. By analysing the flow field distributions of the above two flow channel structures, it can be seen that the electrolyte velocity in the machining gap of Scheme 1 is higher than that of Scheme 2 and that the liquid supply is sufficient, while the gap flow field of Scheme 2 is more stable than that of Scheme 1.
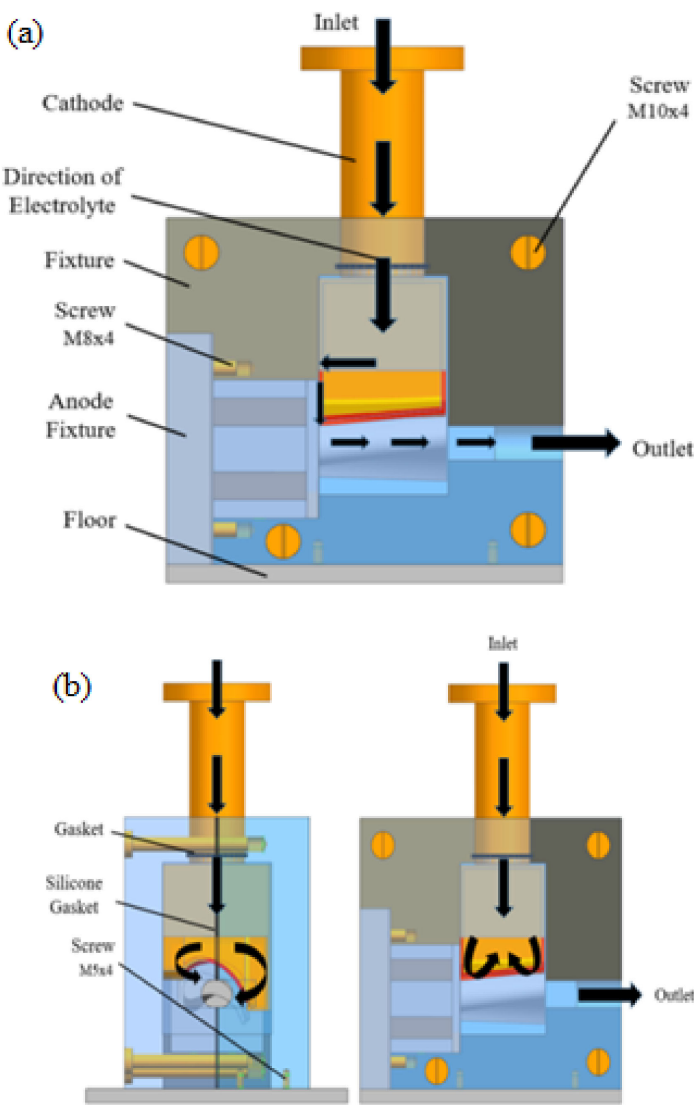

Figure 7. Fixture flow channel structure. (a) Scheme 1 and (b) Scheme 2 .

\subsection{Optimization of the initial flow field in the vertical electrochemical machining of aero-rotor blades}

\subsubsection{Optimization of the initial flow field structure in the} vertical electrochemical machining of aero-rotor blades In summary, in order to ensure the stability of the flow field and the flow rate of the electrolyte at the same time, the problem of an insufficient electrolyte supply at the large curvature of the blade back in Scheme 2 is first optimized by introducing the electrolyte flow channel structure of Scheme 1 into this paper (as shown in Fig. 9(a)), and then a numerical simulation analysis of the optimized flow channel is carried out. As shown in Fig. 9(c), the overall pressure distribution uniformity of the electrolyte in the machining gap is further improved, and there is no sudden pressure drop or negative pressure in the machining gap. While in Fig. 9(d), the electrolyte in the machining gap is sufficient, and the electrolyte decreases significantly in the disorderly area of the outlet, thus further improving the stability of the electrolyte flow in the whole processing gap.

4.2.2 Optimization of the initial flow field structure in the vertical electrochemical machining of aero-rotor blades

Flow field analysis of the optimized flow channel structure shows that the corresponding velocity is small under a stable flow field. It is concluded that the main reason for this phenomenon is that in the design of the simulation parameters of the initial flow field, the flow velocity calculated by the Bernoulli equation is the ideal flow velocity without considering the influence of fluid viscosity. Therefore, to meet the above simulation conditions, a higher inlet velocity is needed to counteract the decrease in the actual velocity due to viscous force. To ensure the stability of the flow field in the machining gap, the flow rate can achieve the above turbulence by changing the pressure matching value of the inlet and outlet; the control variable method is used to divide the pressure 


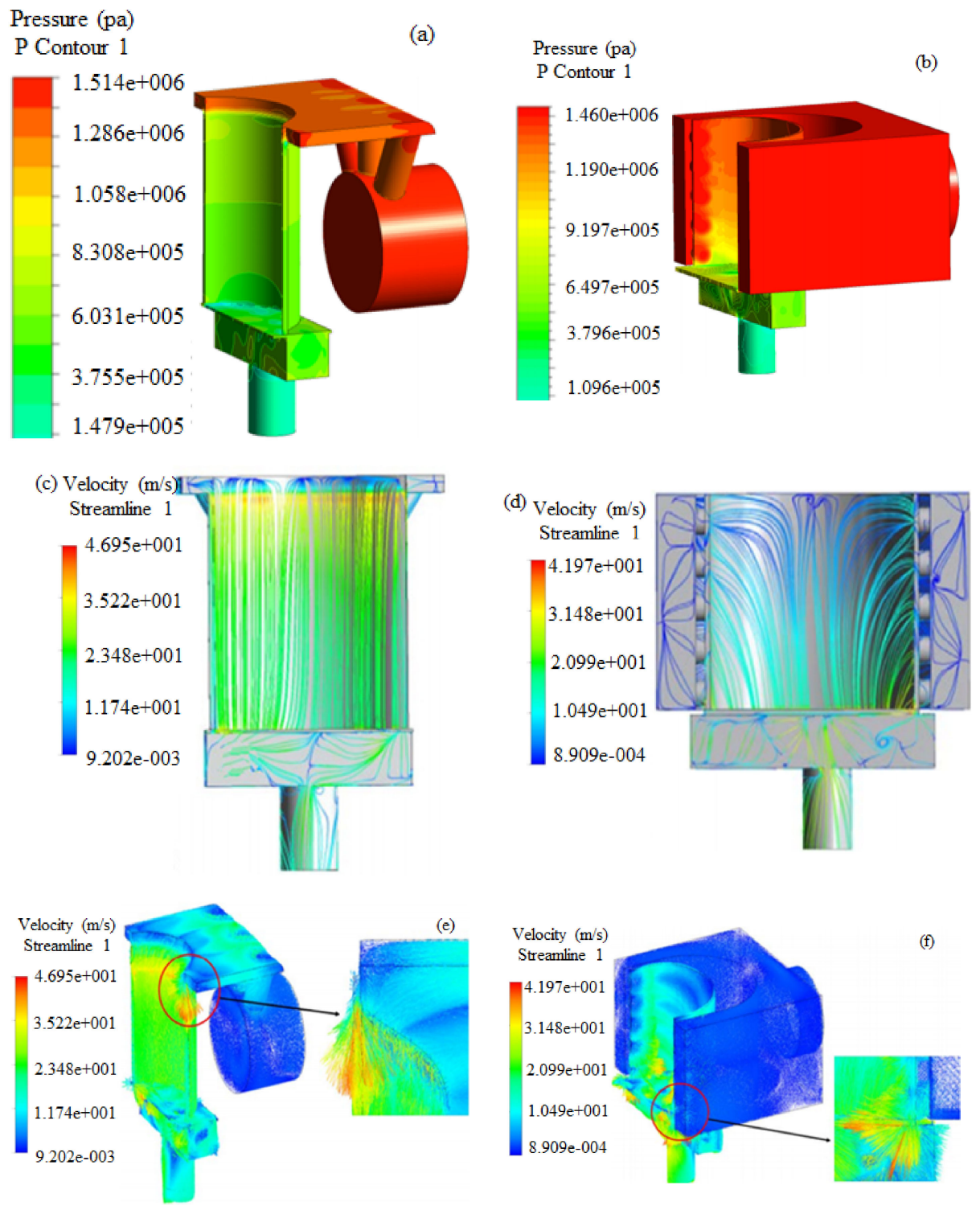

Figure 8. Cloud diagram of the electrolyte flow field parameter distribution (initial flow field). (a) cloud diagram of the electrolyte flow pressure distribution for Scheme 1, (b) cloud diagram of the electrolyte flow pressure distribution for Scheme 2, (c) cloud diagram of the electrolyte flow streamline distribution for Scheme 1, (d) cloud diagram of the electrolyte flow streamline distribution for Scheme 2, (e) cloud diagram of the electrolyte flow velocity vector distribution for Scheme 1, and (f) cloud diagram of the electrolyte flow velocity vector distribution for Scheme 1.

into three degrees: high, medium and low, to find the optimal pressure matching value as follows; the initial flow rate $u_{0}$ is $15 \mathrm{~m} \mathrm{~s}^{-1}$, the inlet pressure $P_{\mathrm{A}}$ is $2.4 \mathrm{MPa}$ and the outlet pressure $P_{\mathrm{B}}$ is $0.2 \mathrm{MPa}$.

As described in 3.1.1, the inlet pressure $P_{\mathrm{A}}$ is ca. $1.5 \mathrm{MPa}$, and the outlet pressure is changed. According to Fig. 10(a), with increasing outlet pressure, the flow rate in the machining gap decreases gradually, and the electrolyte flow rate is the largest when the outlet pressure is $0 \mathrm{MPa}$, while the uniformity of the electrolyte flow rate increases with increasing outlet pressure (as shown in Figs. 10(b)-10(c)). Therefore, under the condition of a uniform gap electrolyte pressure distribution, a higher gap electrolyte flow rate, $P_{\mathrm{B}}=0.2 \mathrm{MPa}$, is selected.

As described in 3.1.1, the outlet pressure $P_{\mathrm{B}}$ is $0.2 \mathrm{MPa}$, and the inlet pressure is changed. According to Fig. 10(d), with increasing inlet pressure, the flow rate in the machining gap increases gradually, and when the inlet pressure $P_{\mathrm{A}} \geq 2.4 \mathrm{MPa}$, the electrolyte flow rate of the machining gap meets the turbulence condition.
The electrolyte velocity increases along the gap flow, which is beneficial to the discharge of electrolyte products and bubbles. Therefore, the inlet pressure should be more than 2.4 MPa, but an excessive electrolyte flow rate may cause unstable effects such as cathodic vibration during processing, so an inlet pressure of $P_{\mathrm{A}}=2.4 \mathrm{MPa}$ is selected, simultaneously combining the maximum value of the pressure pump of the machine tool with the appropriate flow rate.

Therefore, the flow fields of the blade back surface and the blade basin surface are optimized by this method, and the corresponding optimized flow field simulation results are obtained as shown in Fig. 11.

\subsection{Process verification of the optimized flow field for aero- rotor blades}

In order to verify the rationality of the above optimization scheme, the original (as shown in Fig. 12(a)) and optimized flow channel (as shown in Fig. 12(b)) of Scheme 2 and the correspond- 
(a)
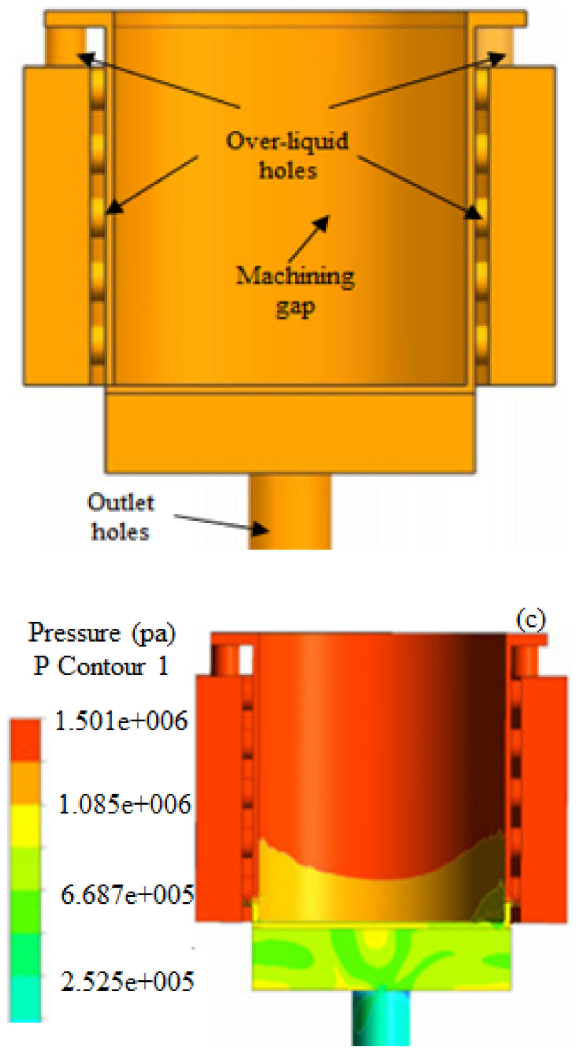

(b)
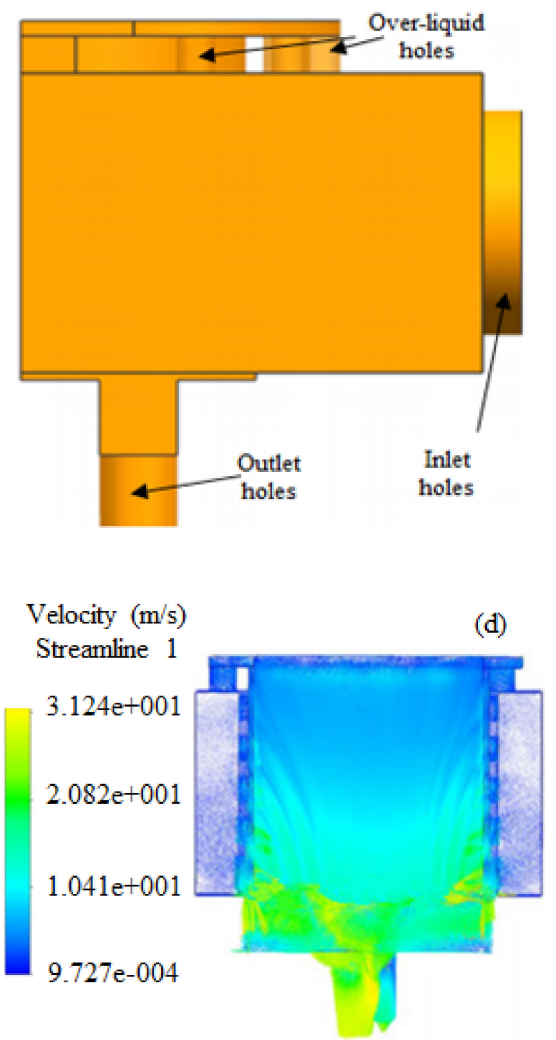

Figure 9. Optimization of the flow channel structure of Scheme 2. (a) structure of the optimized flow channel (front view), (b) structure of optimized flow channel (side view), (c) cloud diagram of the electrolyte flow pressure distribution for optimized flow channel, (d) cloud diagram of the electrolyte velocity distribution for optimized flow channel.

ing fixture (as shown in Fig. 12(c)) are used in this paper, and the surface error (as shown in Figs. 12(e) and 12(f), the error variation and error distribution of adjacent measuring points are reflected by using the method of scattered point broken line diagram) and surface roughness (as shown in Table S1, this paper combined with the length and width of the blade surface, 20 sampling points on the blade surface are selected at equal distance, and the average value of these sampling points is taken as the roughness representative value of each sampling point three times) of aero-rotor blade were analyzed by using three coordinate measuring instrument and roughness measuring instrument, respectively.

The surface error range of the blade processed by the original Scheme 2 is between 0.02 and $0.23 \mathrm{~mm}$, the average error of the blade is $0.12 \mathrm{~mm}$, the larger error is mainly concentrated near the blade edge, and the simulation results are verified. The error range of the blade processed by the optimized Scheme 2 is between 0.02 and $0.12 \mathrm{~mm}$ and the average error of the blade is $0.07 \mathrm{~mm}$, which has high accuracy. Moreover, the optimization scheme has higher stability and a more uniform distribution than the original scheme, regardless of the blade back surface error or blade basin surface error. The average surface roughness of the blade processed by Scheme 2 is $1.76 \mu \mathrm{m}$, and the surface roughness near the blade edge is low, and the average surface roughness of the blade processed by the optimized scheme is $1.16 \mu \mathrm{m}$, so the quasi-consistency and feasibility of the design idea are verified.

Furthermore, according to Fig. 12 and, it can be noted that the machining quality in the optimization scheme decreases gradually with the process. It is considered that the causes of this phenomenon are: On the one hand, in the process of electrolytic processing combined with Fig. 1 it can be seen that the Inconel ${ }^{\circledR} 718$ is the Ni$\mathrm{Cr}-\mathrm{Fe}$ base three-phase alloy, which will form the corresponding hydrogen products and ionic salt products in the electrolyte through hydration reaction and redox reaction under the forced action of external power supply potential. Because the effect of hydrogen in the electrolyte is equivalent to resistance, and the ionization of ionic salts in the electrolyte will further improve the conductivity of the electrolyte through the ion mass transfer effect in the flowing electrolyte, and considering that both phenomena are based on liquid mass transfer, therefore, with the accumulation of these two terms, the influence on conductivity is becoming more and more significant; On the other hand, due to the above alloy produce corresponding heat when hydration reaction and redox reaction occur, and the heat of the reaction is also based on the liquid phase mass transfer process, which further adjusts the conductivity of electrolyte electricity by further affecting the ion mass transfer rate and gas mass transfer rate and finally feeds back to the macroscopic erosion process. Therefore, this is the multi-physical field coupling mechanism of the temperature field acting on the electric field by changing the flow field, which is also the main reason for the error of the model with the variation along the path.

\section{Conclusion}

In this paper, the flow field of aero-blade in vertical electrochemical machining was analysed and the following conclusions are obtained:

1. By designing the flow channel structure which combines with the electrolyte characteristics of positive flow and side flow, the problem of cavities can be avoided due to large pressure drop when entering the machining gap by adding electrolyte in the side wall; Meanwhile, the vertical direction of liquid intake at the machining gap can ensure that the electrolyte 
(a)
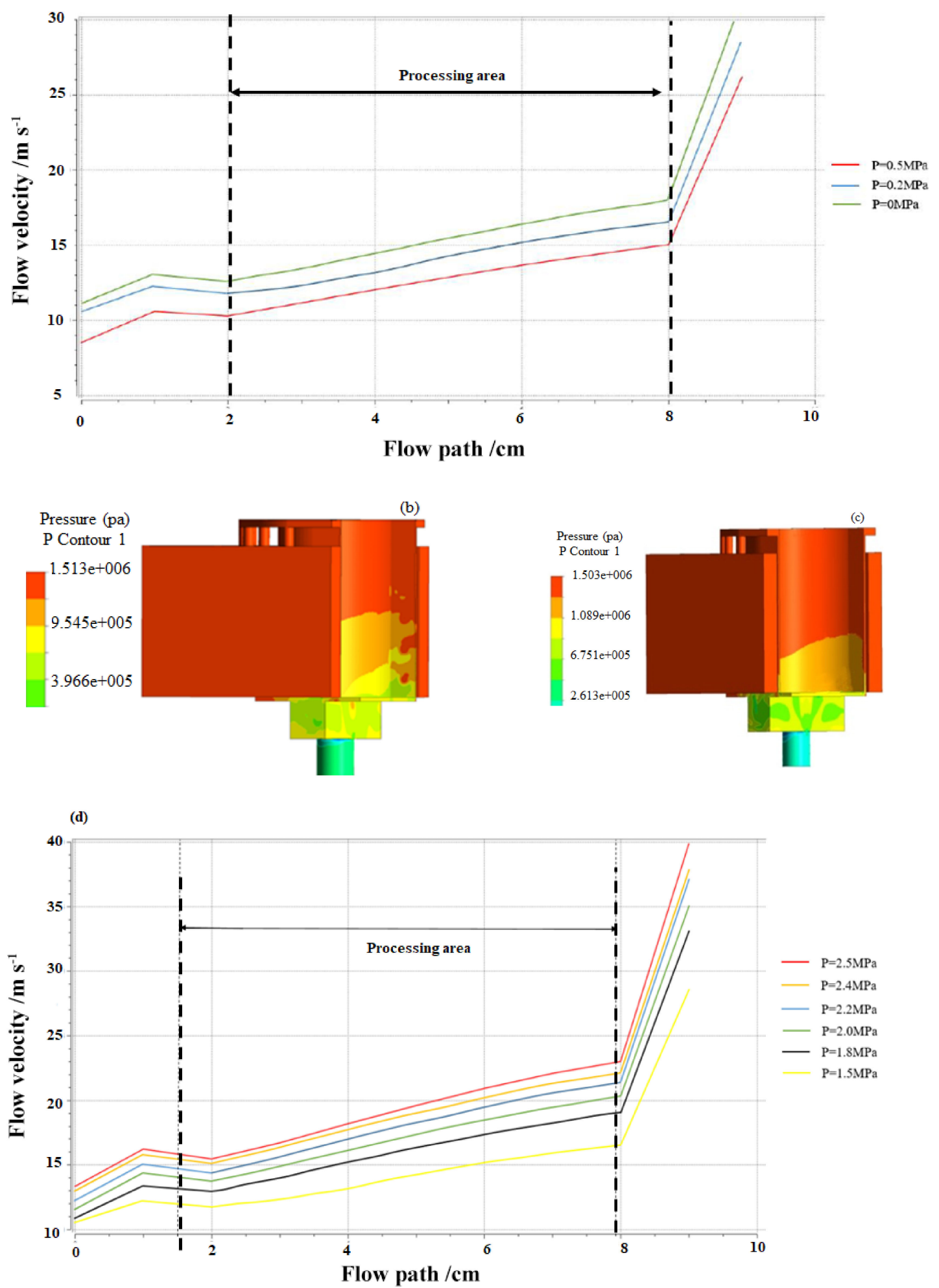

Figure 10. Analysis of the relationships between different processing parameters and the flow field. (a) Flow rate of the interstitial electrolyte under different outlet pressures (local), (b) $P_{\mathrm{B}}=0 \mathrm{MPa}$, (c) $P_{\mathrm{B}}=0.2 \mathrm{MPa}$, (d) Flow rate of the interstitial electrolyte under different inlet pressure (local).

flow rate in the machining gap is not affected by the change of blade curvature that resulting in the problem of insufficient liquid supply.

2. By analyzing the mechanism of each flow field parameter, the inaccuracy of the designed flow channel structure using Bernoulli idealized fluid as the initial condition is avoided, and the initial process parameters and the corresponding flow channel structure are optimized together. Moreover, the verification test shows that this optimized flow structure has high machining quality (surface error: $0.02-0.12 \mathrm{~mm}$; the average surface error: $0.07 \mathrm{~mm}$; the surface roughness: $1.16 \mu \mathrm{m})$. 

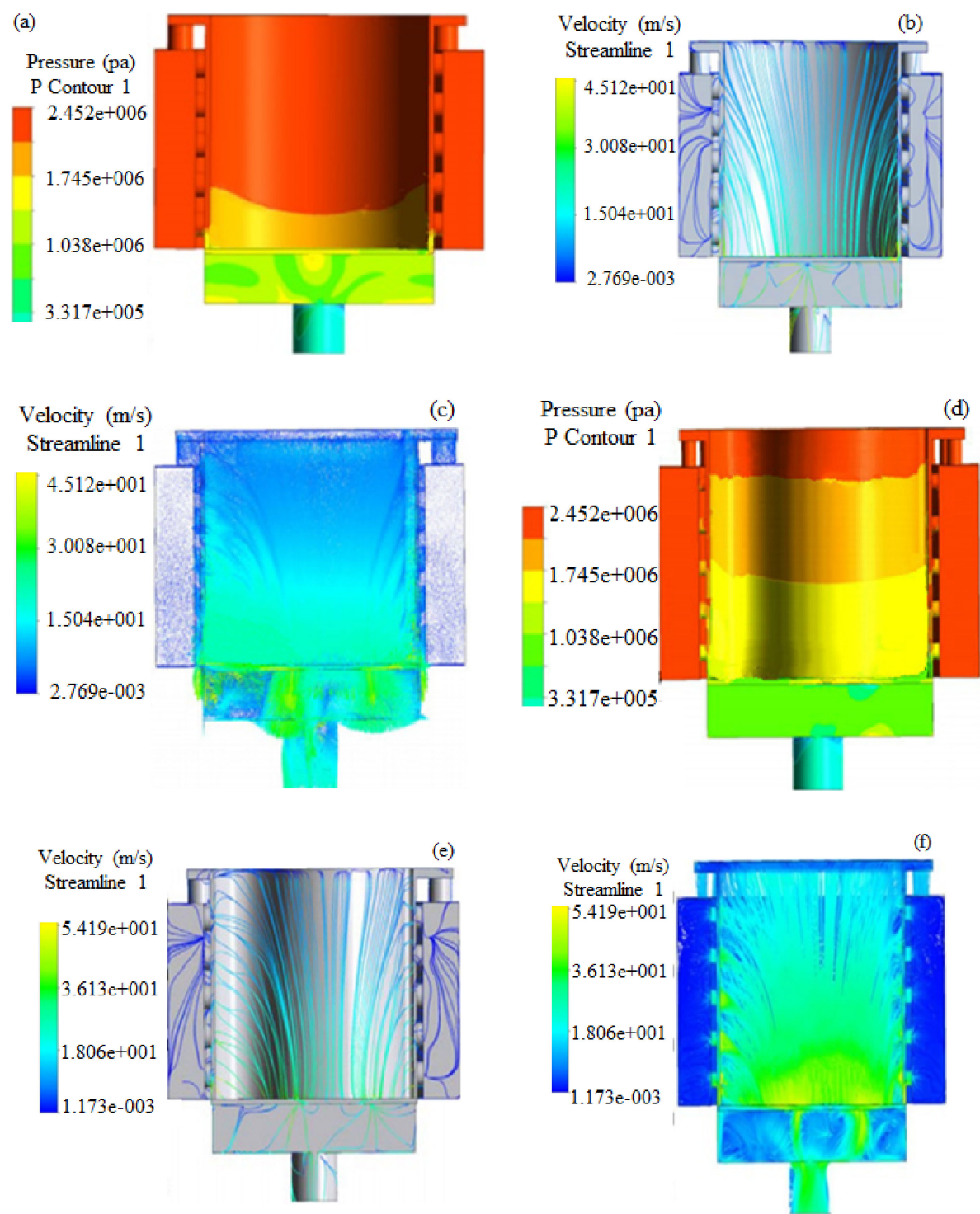

Figure 11. Analysis of the optimal flow field of aero-rotor blades. (a) cloud diagram of the electrolyte flow pressure distribution for blade back flow channel, (b) cloud diagram of the electrolyte flow streamline distribution for blade back flow channel, (c) cloud diagram of the electrolyte velocity distribution for blade back flow channel, (d) cloud diagram of the electrolyte flow pressure distribution for blade basin flow channel, (e) cloud diagram of the electrolyte flow streamline distribution for blade basin flow channel, (f) cloud diagram of the electrolyte velocity distribution for blade basin flow channel.

3. At the same time, it can be noted that the machining quality in the optimization scheme decreases gradually with the process. It is considered that the Inconel ${ }^{\circledR} 718$ is the Ni-Cr-Fe base three-phase alloy, which will produce ionic products and hydrogen in electrochemical machining, and change the conductivity between electrodes by liquid-phase mass transfer, thus affecting the corrosion state of each part of the electrode; on the other hand, the electrochemical reaction of the anode material in the electrolyte will produce a temperature field, and this part of the heat will change the above ion mass transfer, liquid-phase mass transfer and the volume fraction of hydrogen, and finally feedback the electric field through the flow field to form the final corrosion effect.

\section{Supporting Information}

The Supporting Information is available on the website at DOI: https://doi.org/10.5796/electrochemistry.21-00025.

\section{Acknowledgments}

This research is funded by National Natural Science Foundation of China (NSFC) under grant number 51705392, the project of 2019 Shaanxi Provincial Innovation Ability Support Program under grant number 2019PT-19.

Authors' contributions conceptualization, Liang Huang and Yan Cao; methodology, Liang Huang and Chunlei Tian; validation, Liang Huang, Yuanfei Wang and Jiang Du; formal analysis, Liang Huang and Chunlei Tian; investigation, Jiang Du and Ruochen Zhao; resources, Yuanfei Wang; writing-original draft preparation, Liang Huang and Yan Cao; writing-review and editing, Liang Huang; project administration, Yan Cao and Yuanfei Wang; funding acquisition, Yan Cao and Jiang Du.

Funding This research is funded by National Natural Science Foundation of China (NSFC) under grant number 51705392, the project of 2019 Shaanxi Provincial Innovation Ability Support Program under grant number 2019PT-19.

Availability of data and materials The data used to support the 

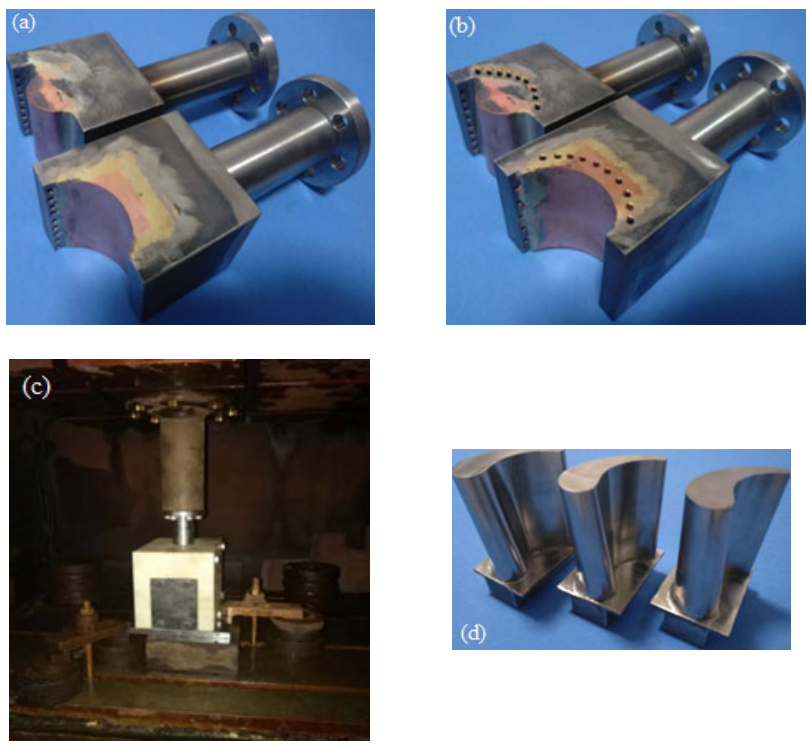

(e)
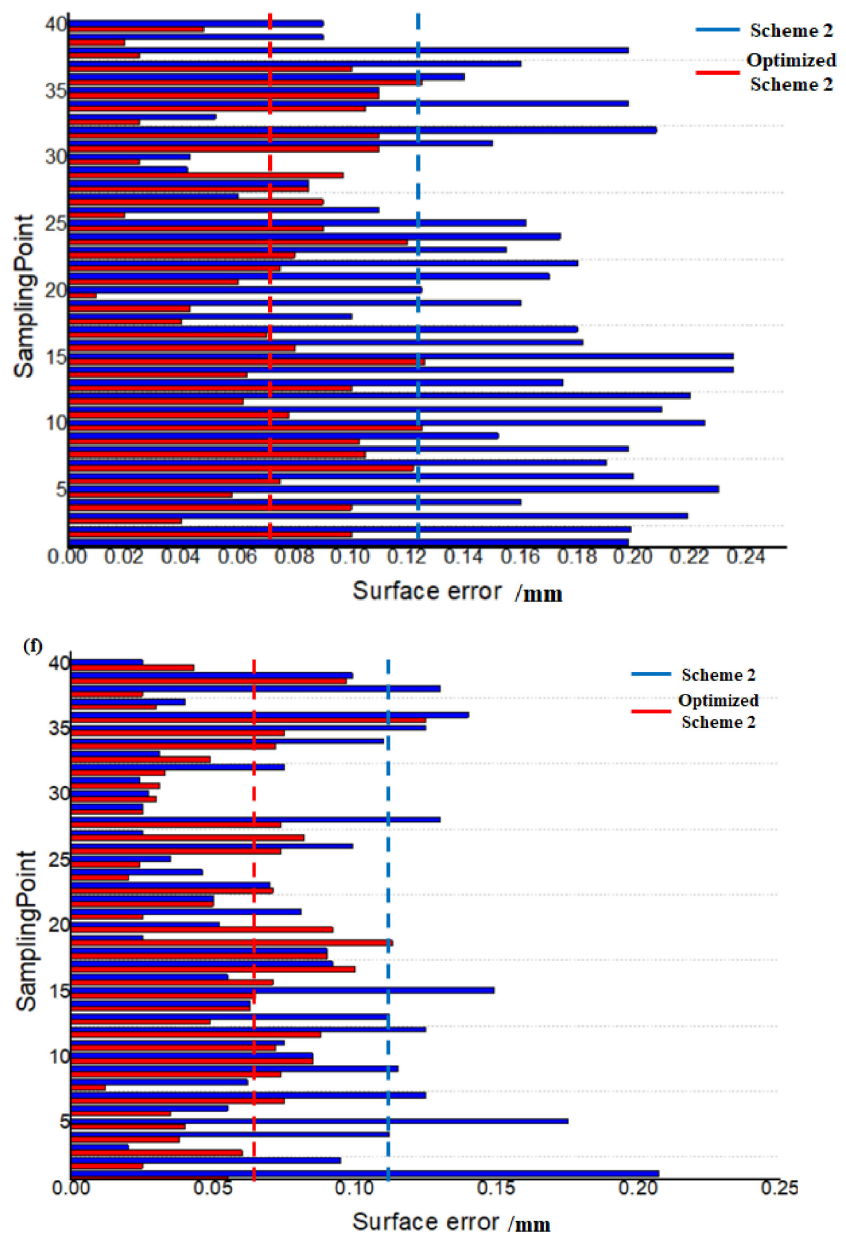

Figure 12. Experimental verification of the electrochemical machining of aero-rotor blades. (a) initial flow channel, (b) optimized flow channel, (c) fixture, (d) final products, (e) surface error of the blade basin, (f) surface error of the blade back. findings of this study are available from the corresponding author upon request.

Conflicts of Interest The authors declare that there are no conflicts of interest regarding the publication of this article.

\section{References}

1. B. W. Wang, W. Z. Tang, and L. K. Song, Structures, 28, 1634 (2020).

2. N. Kozak, F. Xu, and M. R. Rajanna, J. Mech., 36, 595 (2020).

3. H. Y. Gu, A. D. Shaw, M. Amoozgar, J. Zhang, C. Wang, and M. I. Friswell, Compos. Struct., 254, 112855 (2020)

4. Q. L. Hao and Q. Yang, Int. J. Adv. Manuf. Technol., 111, 1415 (2020).

5. H. González-Barrio, A. Calleja-Ochoa, A. Lamikiz and L. N. López de Lacalle, Appl. Sci., 10, 3063 (2020).

6. C. H. Zhao, N. S. Qu, and X. C. Tang, Precis. Eng., 29, 569 (2019).

7. Y. D. Wang, Z. Y. Xu, and J. C. Hu, Mater. Today Commun., 25, 7 (2020).

8. D. Zhu, X. Y. Hu, and J. H. Lin, Mach. Sci. Technol., 24, 489 (2020).

9. Z. Y. Xu, D. Zhu, and L. Wang, J. Mech. Eng., 44, 189 (2008).

10. J. Liu, Z. Xu, L. Wan, D. Zhu, and D. Zhu, Acta Aeronauticaet Astronautica Sinica, 35(1), 259 (2014) [in Chinese].

11. J. Sawicki and J. Paczkowski, The European Physical Journal Conference, 92 , 02078 (2015)

12. Y. L. Chen, X. C. Zhou, and P. X. Chen, Chin. J. Aeronaut., 33, 1057 (2020).

13. Y. B. Zeng, L. C. Meng, and X. L. Fang, J. Electrochem. Soc., 164, E408 (2017).

14. D. Deconinck, D. Van, and C. Albu, Electrochim. Acta, 56, 5642 (2011).

15. H. K. Versteeg and W. Malalasekera, An Introduction to Computational Fluid Dynamics: The Finite Volume Method, 2nd Ed., Pearson Education, UK, p. 157 (2007).

16. R. P. Anjos, R. D. Medronho, and T. S. Klein, J. Turbul., 1, 32 (2020).

17. J. W. Xu, D. Zhu, and J. H. Lin, Int. J. Adv. Manuf. Technol., 107, 1551 (2020). 